\title{
Mass detection of bacteriuria by combination of two screening tests
}

\author{
P. Papanayiotou \\ M.D.(Athens) \\ Research Associate in Medicine, \\ Instructor in Bacteriology
K. Papanayiotou M.D.(Athens) \\ Research Assistant in \\ Medicine and Bacteriology
}

\author{
A. S. Dontas \\ M.D.(Athens), M.Sc.(Michigan) \\ Associate Professor of Medicine
}

S. G. MARKETOS

M.D.(Athens)

Assistant Professor of Medicine

Department of Clinical Therapeutics, Alexandra Hospital University of Athens;
and Centre of Studies of Age Related Changes in Man, Athens, Greece

\section{Summary}

The Uriglox screening test was compared with the modified Griess Nitrite test and with standard urine cultures in the detection of significant bacteriuria on 400 ambulant and asymptomatic residents of the Athens Home for the Aged. The modified Nitrite test alone detected $62 \%$, and the Uriglox test $79 \%$ of the 103 cases with positive urine cultures in the examined group. There was significant overlap in the positive cases picked up by each screening test separately, the Uriglox test identifying more Klebsiella infections. Since there were no false-positive cases with either one of the employed tests, the cases identified by one or the other or both screening tests amounted to $95 \%$ of the total number of bacteriuric samples. The combination of the moderately sensitive but highly specific test of Nitrite, with the very sensitive test of Uriglox, can effectively substitute for the expensive and timeconsuming quantitative bacterial counts with pourplate techniques in mass screening for bacteriuria.

\section{Introduction}

There is still need for a simple, sensitive, specific and low cost screening test for the mass detection of bacteriuria. The need is particularly important in the screening of groups with high prevalence rates of urinary tract infections, such as in pregnancy or in old age, particularly if clinical symptoms are scanty. Early and accurate recognition of bacteriuria in these groups is important because a significant number of patients with urinary tract infections are diagnosed too late for treatment to be effective.
We have compared the results of two screening tests for significant levels of bacteriuria, the recently introduced Uriglox test and a modified Nitrite test, (B.M. test), against each other and against the standard pour-plate technique, in a large group of elderly subjects with a wide prevalence of bacteriuria.

\section{Methods}

The study was conducted in the months of August and September, 1969, on 440 ambulant residents of the Athens Home for the Aged, 120 males and 320 females, with mean age $77.4 \pm 11.8$ years. No subject with a history of prostatic enlargement or who was bed-ridden was included in the study. Following instructions on the previous evening regarding a small dinner and avoidance of fluids, and after cleansing of the external genitalia with soapy water, midstream specimens of the first voiding of the day were collected by the third co-author. The urine samples were first examined for protein and glucose and then were tested, within $10 \mathrm{~min}$ of their collection, (a) with the modified Griess nitrite method (Cruickshank \& Moyes, 1914; Smith et al., 1961; Smith \& Schmidt, 1962), (b) with the glucose consumption detecting test (Scherstén \& Fritz, 1967; Scherstén, Fritz \& Köhler, 1967). All samples giving a positive response for bacteriuria with either one of the two methods were immediately cultured by a spread-plate technique. McConkey-agar plates were inoculated with $0.1 \mathrm{ml}$ of a tenfold dilution of urine, and a blood-agar plate was used for the detection of 
Gram-positive organisms. Further, every third urine specimen giving a negative reaction with both the Nitrite and Uriglox tests was also cultured immediately (total 105 cultures), to indicate the rate of false-negative results with both screening tests.

\section{Results}

Of the 440 urine specimens studied, forty gave a strongly positive reaction for glycosuria, i.e. the subjects were either diabetic or had gross renal glycosuria. Since the Uriglox test can not be employed as a screening test in the presence of large amounts of urinary glucose, these cases, four of whom gave a positive response with the Nitrite test, are not subjected to further analysis herein.

Fifty-one samples (eleven from males and forty from females) gave a positive test for bacteriuria with both the Nitrite and the Uriglox tests. Further, thirteen samples (four males, nine females) were positive only with the Nitrite test, and thirty samples (six males, twenty-four females) were positive only with the Uriglox test. All these ninety-four samples proved to have significant bacteriuria, i.e. more than 100,000 organisms per $\mathrm{ml}$ by the spread-plate technique. Further, in a sample of 105 of the 305 urine specimens negative with both screening tests, three had significant bacteriuria by the direct culture. This rate of $2.9 \%$ false-negative results has been assumed to prevail in the remaining material in the estimation of false-negatives.

The proportion of the total cases of bacteriuria detected by the two tests singly or in combination, i.e. the sensitivity of the tests, is indicated in Table 1 .

TABLE 1

\begin{tabular}{cccccc}
\hline & \multicolumn{3}{c}{ Sensitivity* } & \\
\multicolumn{2}{c}{ Nitrite } & \multicolumn{2}{c}{ Uriglox } & \multicolumn{2}{c}{ Either test } \\
\hline \multicolumn{2}{c}{ True } & False & True & False & \multicolumn{2}{c}{ True } & False \\
positive & negative & positive & negative & positive & negative \\
$62 \cdot 1$ & 37.9 & $78 \cdot 6$ & $\mathbf{2 1 \cdot 4}$ & $\mathbf{9 7 \cdot 2}$ & $\mathbf{2 \cdot 8}$ \\
\hline
\end{tabular}

Rates expressed in per cent of cases

*Sensitivity in detecting positives

The 'total' number of cases was 103, estimated from the sum of all positive samples detected with either one of the screening tests, plus nine cases representing the estimated number of false-negatives in the remaining 306 samples on the basis of the rate obtained on the 105 cultured samples.

The percentage of false-positive results was zero with either screening test; i.e. all positives with either test gave a significant bacteriuria with direct culture; stated otherwise the two tests in our series proved absolutely specific in reporting positives, in that they did not report false-positives (Rose \& Blackburn, 1968).
The microorganisms cultured from the ninetyfour cases identified as positives by either one or both screening tests are indicated in Table 2 . As expected

TABLE 2. Microorganisms from urine cultures of bacteriuric subjects

\begin{tabular}{lcc}
\hline \multicolumn{1}{c}{ Species } & $\begin{array}{c}\text { Number of } \\
\text { cases }\end{array}$ & $\begin{array}{c}\text { Per cent } \\
\text { of total }\end{array}$ \\
\hline Escherichia coli & 70 & $74 \cdot 4$ \\
Proteus vulgaris & 7 & $7 \cdot 4$ \\
Klebsiella pneumoniae & 7 & $7 \cdot 4$ \\
Enterococcus & 2 & $2 \cdot 2$ \\
Staphylococcus aureus & 2 & $2 \cdot 2$ \\
Alcaligenes faecalis & 2 & $2 \cdot 2$ \\
Mixed & 4 & $4 \cdot 2$ \\
\hline
\end{tabular}

in this largely non-manipulated sample of subjects the percentage of Escherichia coli infections amounted to three-fourths of the total cases. Further, only three of the seven cases of Klebsiella pneumoniae infections were identified by the Nitrite test, the Uriglox identifying all seven. The three cases falsely reported as negative by both tests were two typical and one atypical (Citrobacter) Escherichia coli strains.

\section{Discussion}

Bacteriuria, which plays a key role in the pathogenesis of chronic renal infection (Kass \& Zinner, 1969), cannot be easily ascertained with quantitative urine culture techniques in the home, in general practice and in smaller hospitals with limited laboratory facilities, or finally in large scale epidemiological studies (Bulger \& Kirby, 1963; Leigh \& Williams, 1964; Thysell, 1969). Even in larger hospitals the material costs and laboratory technicians' time for dilution techniques create special problems, which could be minimized if one or more proper screening procedures would eliminate several cases of negative urine specimens. The significance of this problem becomes obvious since: (a) bacteriuria is an entity with highly variable course and high turn-over rate, i.e. often clearing spontaneously and reappearing in an approximately equal number of cases, therefore necessitating repeated check-ups of the subjects under study, (b) the recognition of significant bacteriuria constitutes the best available diagnostic index of urinary tract infection, and (c) detection of bacteriuria is a cardinal criterion for the follow-up of the response to the treatment in individual cases, especially in the clinically occult phase of pyelonephritis.

The modified Nitrite test, which was employed in the present study, has a high specificity although its sensitivity is rather low (Kincaid-Smith, Bullen \& Mills, 1964). On the other hand, the Uriglox test is reported to have a much higher sensitivity and a high specificity as well (Scherstén et al., 1968). The 
results of the present study indicate that the combination of these two single screening tests achieves both a high degree of sensitivity $(95 \%$ of the positive cases subsequently detected by the urine culture) and a high degree of specificity $(100 \%$ in reporting positives, $97 \%$ in reporting negatives). This is achieved because the limitations of the Uriglox test (glycosuria and Pseudomonas infections) are compensated by the Nitrite test and vice versa. Therefore, the two combined tests studied offer distinct advantages and should be recommended for routine diagnostic purposes, in all cases, where repeated urine cultures can not be easily obtained.

\section{Acknowledgments}

Uriglox strips were kindly donated by $\mathrm{Mr}$ Bertil Järnhäll, ABKABI, Stockholm. The authors are indebted to Professor B. K. Malamos and Mrs B. Kefakis for critical suggestions regarding the project and the manuscript.

Supported by grants from the Greek Ministry of Social Services and the Royal Hellenic Research Foundation.

\section{References}

Bulger, R.J. \& Kirby, W.M. (1963) Simple tests for significant bacteriuria. Archives of Internal Medicine, 112, 742.

Cruickshank, J. \& Moyes, J.M. (1914) The presence and significance of nitrites in urine. British Medical Journal, $2,712$.
KASS, E.H. \& ZINNER, S.H. (1969) Bacteriuria and renal disease. Journal of Infectious Diseases, 120, 27.

Kincaid-Smith, P., Bullen, M. \& Mills, J. (1964) The reliability of screening tests for bacteriuria in pregnancy. Lancet, ii, 61 .

Leigh, D.A. \& Williams, J.D. (1964) Methods for detection of significant bacteriuria in large groups of patients. Journal of Clinical Pathology, 17, 498.

Rose, G.A. \& Blackburn, H. (1968) Cardiovascular Survey Methods. WHO monograph, Series 56, 188. World Health Organization, Geneva.

Scherstén, B., Dahlqvist, A., Fritz, H., Köhler, L. \& WESTLUND, L. (1968) Screening for bacteriuria with a test paper for glucose. Journal of the American Medical Association, 204, 205.

Scherstén, B. \& Fritz, H. (1967) Subnormal levels of glucose in urine. A sign of urinary tract infection. Journal of the American Medical Association, 201, 949.

SCherstén, B., Fritz, H. \& KöHLER, L. (1967) Subnormal concentration of urinary glucose as a sign of urinary tract infection in children. Acta Paediatrica Scandinavica, 57, 54 (Suppl. 177).

Smith, L.G. \& Schmidt, J. (1962) Evaluation of three screening tests for patients with significant bacteriuria. Journal of the American Medical Association, 181, 431.

Smith, L.G., Thayler, W.R., Malta, E.M. \& Utz, J.P. (1961) Relationship of the Griess nitrite test to bacterial culture in the diagnosis of urinary tract infection. Annals of Internal Medicine, 54, 66.

Thysell, H. (1969) Evaluation of chemical and microscopical methods for mass detection of bacteriuria. Acta Medica Scandinavica, 185, 393. 